\title{
Protection of the goose barnacle Pollicipes pollicipes, Gmelin, 1790 population: the Gaztelugatxe Marine Reserve (Basque Country, northern Spain)
}

\author{
ÁNGEL BORJA, IÑIGO MUXIKA and JUAN BALD \\ AZTI - Tecnalia. Marine Research Division Herrera Kaia, Portualdea s/n 20110 Pasaia. Spain. E-mail: aborja@pas.azti.es
}

\begin{abstract}
SUMMARY: Marine protected areas are expected to play a prominent role in the conservation of marine resources and fisheries management. In the Basque Country (northern Spain) the small Marine Reserve of Gaztelugatxe (158 ha) was established in 1998. One of the aspects taken into account in protecting this area was the overexploitation of the goose barnacle Pollicipes pollicipes. Now, after five years of protection, differences in density, biomass, size and weight of the goose barnacle are investigated inside the protected area (Aketze and Gaztelugatxe locations) and outside of it, at the nearest locations (Izaro and Ogoño) which have been continuously exploited. This contribution demonstrates that the reserve could be an efficient tool in preserving the goose barnacle populations in the area. Hence, density, biomass and allometric coefficients are higher in the protected areas. These locations are also associated with higher percentages of juveniles, together with a high number of large-sized individuals.
\end{abstract}

Keywords: goose barnacle, exploitation, conservation, resources, marine reserve, wave exposure.

Resumen: CONSERVACIÓN DE LAS POBlaCiONES DE PERCEBe (PolLICIPES POLLICIPES, GMELIN, 1790) EN LA RESERVA MARINA DE GazTelugatXe (País VAsCo, NORTE DE EsPaÑa). - Las áreas marinas protegidas juegan un papel relevante en la conservación de los recursos marinos y la gestión de pesquerías. En el País Vasco (norte de España) se creó la pequeña (158 Ha) reserva marina de Gaztelugatxe en 1998. Uno de los aspectos más importantes para su protección fue la sobreexplotación a la que se encontraba sometido el percebe Pollicipes pollicipes. Tras cinco años de protección se llevó a cabo un estudio para investigar las diferencias en densidad, biomasa, tamaño y peso de los percebes, tanto dentro del área protegida (Aketze y Gaztelugatxe), como fuera de ella, en las cercanas localidades de Izaro y Ogoño, que han sido explotadas permanentemente. Los resultados del estudio demuestran que la reserva es una herramienta adecuada para preservar las poblaciones de percebe en la zona. Así, la densidad, biomasa y los coeficientes alométricos son mayores en las áreas protegidas. Estas zonas presentan también mayores porcentajes de juveniles y un mayor número de individuos de gran tamaño, por comparación con las zonas explotadas.

Palabras clave: percebe, explotación, conservación, recursos, reservas marinas, exposición al oleaje.

\section{INTRODUCTION}

Marine protected areas are expected to play a prominent role in the conservation of marine resources and fisheries management, as advocated by international organisations, such as the World Conservation Union (Attwood et al., 1997). There are many types of marine protected areas worldwide, with different conservation goals, such as: (i) protecting habitats; (ii) managing sensitive species; (iii) protecting biodiversity; or even, (iv) fisheries management (Jamieson and Levings, 2001; Botsford et al., 2003).

The World Conservation Union proposed the goal of conserving $20 \%$ of the world's coastline with marine protected areas by the year 2000 (IUCN, 1992). In the case of the Basque Country (northern Spain), the Basque Department of 
Agriculture and Fisheries decided in 1993 to create a network of marine reserves along the coast, with the following aims: (i) to protect marine resources including habitats and threatened species of commercial and ecological interest; and (ii) to integrate several ecosystems along the coast, acting as 'natural spreading areas' (Castro et al., 2004) for several species. A preliminary selection of the most interesting sites along the coast was undertaken in 1994 (Borja et al., 1999), based on ecological, landscape setting and cultural values. Among the areas studied during the 1990s, the most interesting was Gaztelugatxe (Fig. 1); this included submarine caves, rocky marine arches and islands, summer upwelling, and high quality water (in terms of the absence of contaminants and low turbidity levels; see Borja et al., 2000). There was also significant exploitation of the goose barnacle resource, Pollicipes pollicipes. Finally, there are two important species of seabirds nesting in the area: Phalacrocorax aristotelis and Hydrobates pelagicus (Borja et al., 2000; Franco et al., 2004).

The small Marine Reserve of Gaztelugatxe (158 Ha) was created in 1998 (229/1998 Decree of 15 September of the Basque Government), with the aim, amongst others, to protect the goose barnacle populations (Borja et al., 2000) and the subsequent damage of the associated communities, as described in other countries (Jamieson et al., 1999).
Although no data are available on the goose barnacle populations of Gaztelugatxe, before 1998, the Fisheries Service Guard verified the depletion of captures of this species before the creation of the reserve, probably due to overexploitation. The managerial decision to establish the marine reserve was based partially on the hypothesis that prohibiting the exploitation of $P$. pollicipes would result in increased density, biomass and other parameters of this barnacle (Borja et al., 2000). Hence, after five years of protection, several studies were undertaken at this location (Borja et al., 2004).

The present authors have hypothesised on the possibility that the protection afforded in the marine reserve (at Aketze and Gaztelugatxe (Fig. 1)), when compared with non-protected or exploited areas (Izaro and Ogoño) could, for the goose barnacle: (i) increase density, biomass, size and weight; and/or (ii) modify adult-juvenile proportions. However, such differences could be controlled by other factors, such as wave energy, in this particular case, represented by coastal orientation (González et al. (2004) have determined that westerly-oriented coasts receive more wave energy in the Basque Country than easterly-oriented). Similarly, distribution of tidal levels, i.e. intertidal or subtidal, could act as another controlling mechanism. Hence, the objective of this contribution is to determine the suitability of the reserve for protecting the goose barnacle population.

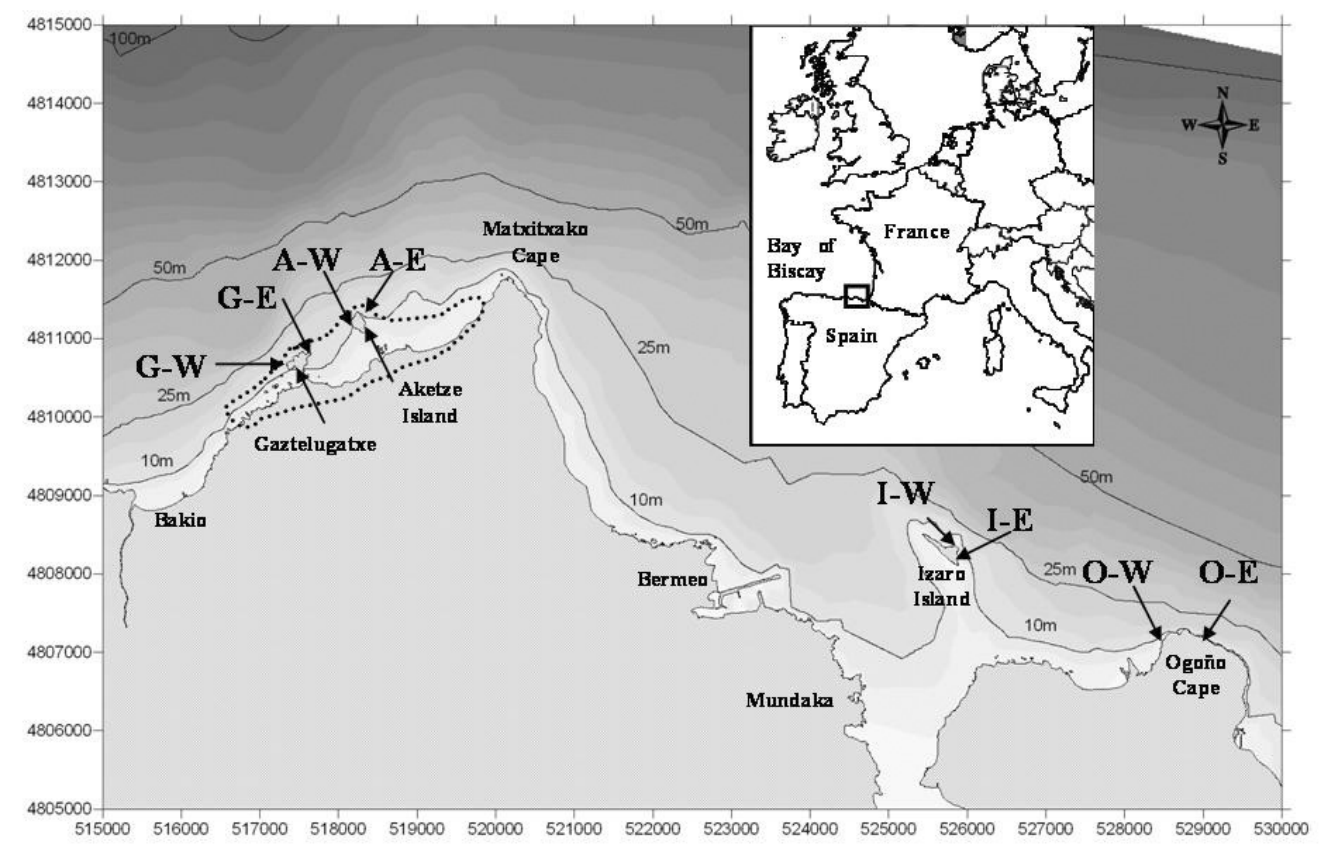

FIG. 1. - Location, within a European context, of the sampling locations used in comparing protected and unprotected (exploited) areas for goose barnacles. The dotted line represents the limits of the Gaztelugatxe Marine Reserve. The coordinates are in UTM. Key: W = northwest-oriented areas; $\mathrm{E}=$ northeast-oriented areas; $\mathrm{G}=$ Gaztelugatxe; $\mathrm{A}=$ Aketze; $\mathrm{I}=\mathrm{Izaro}$; and $\mathrm{O}=\mathrm{Ogoño}$. 


\section{METHODOLOGY}

The absence of quantitative goose barnacle data, prior to establishing the Gaztelugatxe Reserve, prevents some approaches being used, such as the BACI design (Underwood, 1992). Hence, in order to establish possible differences between protected and unprotected areas for goose barnacles, two location groups were selected: (i) the areas of Izaro Island and Ogoño Cape, which are exploited regularly; and (ii) the areas of Aketze Island and Gaztelugatxe tombolo (both inside the marine reserve), which are protected and unexploited (Fig. 1). All of the locations where the goose barnacles were sampled are only accessible by boat. In addition, the effects of coastal orientation were studied: (i) northwest-orientated substrata (NW), receiving high wave energy; and (ii) northeast-orientated substrata (NE), which are more protected from waves. Moreover, in each of the orientations, two different levels were studied: (i) intertidal (I) (samples collected between 1 and $2 \mathrm{~m}$ above the lowest astronomical tide (LAT)); and (ii) subtidal (S) (samples collected between -0.5 and $0 \mathrm{~m}$ water below the LAT). In each of the possible combinations 4 replicates were taken, totalling 64 replicates in 4 locations, 2 orientations and 2 tidal levels.

At each of the locations, the samples were collected on a randomly stratified basis by scraping $30 \times 30 \mathrm{~cm}$ quadrats totally using a metallic spatula (adapting the De la Hoz and García (1993) methodology). All samples were collected between 18 July and 5 August, 2002.

In the laboratory, the individuals were sorted and counted, including both adults and juveniles. Minimum capitulum length for maturity of the female gonad ranges between 12 and $12.5 \mathrm{~mm}$ (Cruz and Hawkins, 1998; Cunha and Weber 2001); similarly, sperm production is achieved in smaller individuals $(10 \mathrm{~mm})$. Hence, in the present contribution goose barnacles $<10 \mathrm{~mm}$ in length were considered as juveniles, and the remainder as adults. Fresh and dry $\left(80^{\circ} \mathrm{C}, 48 \mathrm{~h}\right)$ weights were determined (individually and by sample). Individuals were measured to the lowest millimetre (Bernard, 1988), in terms of: (i) total length (including capitulum and peduncle); and (ii) capitulum length.

Data sets were studied by means of the Statgraphics (C) software, using a Shapiro-Wilks test to analyse if data fitted a normal distribution at each location, orientation and tidal level. As the data sets were not normally distributed, using a three-way ANOVA for comparing the three factors studied simultaneously (location groups, coastal orientation and tidal level), was not possible. Hence, non-parametric statistics were used, including: (i) the Kruskal-Wallis test, to check differences in density, biomass, capitulum length and total length between locations, with non-orthogonal contrasts between protected and non-protected sampling stations, as a post hoc test; (ii) the Kolmogorov-Smirnov test, for comparing tidal levels and orientations; and (iii) regression between the total length (TL), the capitulum length (CL), and the fresh and dry weights (FW, DW), in deriving the allometric relationships.

The regression model selected was the multiplicative $(\mathrm{y}=\mathrm{a} \mathrm{x})$, in studying relationships between length and weight (this is an old allometric model, based on Nomura (1926) and Barybina and Sanina (1975). Likewise, the regression model, in comparing FW and DW, was the simple linear model $(y=a x+b)$, because their relationships are always linear. A comparison between the regression lines was undertaken. In the case of the multiplicative model, the data were previously log-transformed, due to the model requirements.

Finally, the proportion of the mean juvenile-adult abundance was compared using a $t$-test.

\section{RESULTS}

Density and biomass per replicate, individual mean fresh weight, and capitulum and total length data, as obtained from each of the sampling locations, are listed in Table 1 . In terms of density and biomass, significant differences are found between locations $(p<0.05)$, both in terms of coastal orientation (exposed and non-exposed areas, orientated to NW and NE respectively) and tidal levels (Table 2). Density and biomass are always significantly higher $(p<0.05)$ in the protected areas (Aketze and Gaztelugatxe) than in the non-protected areas (Izaro and Ogoño).

Conversely, there are significant differences in capitulum length $(p<0.05)$ between a NE-orientated coast (non-exposed stations), at both tidal levels (Table 2). For this variable, there are no significant differences between protected and non-protected areas at the subtidal level. However, there are differences at the intertidal level $(p<0.05)$, where the mean capitulum length is higher. 
TABLE 1. - Density and biomass, mean total length (TL), mean capitulum length (CL) and mean fresh weight (FW), of each of the replicates sampled at different orientations, tidal levels and from exploited and unexploited (protected) areas.

\begin{tabular}{|c|c|c|c|c|c|c|c|c|c|c|c|}
\hline \multirow[b]{2}{*}{ Orientation } & \multirow[b]{2}{*}{$\begin{array}{l}\text { Tidal } \\
\text { Level }\end{array}$} & \multicolumn{5}{|c|}{ UNEXPLOITED AREAS } & \multicolumn{5}{|c|}{ EXPLOITED AREAS } \\
\hline & & $\begin{array}{c}\text { Density } \\
\text { (ind.sample }{ }^{-1} \text { ) }\end{array}$ & $\begin{array}{l}\text { Biomass } \\
\left(\text { g.sample }{ }^{-1}\right)\end{array}$ & $\begin{array}{c}\mathrm{TL} \\
(\mathrm{mm})\end{array}$ & $\begin{array}{l}\mathrm{CL} \\
(\mathrm{mm})\end{array}$ & $\begin{array}{l}\mathrm{FW} \\
(\mathrm{g})\end{array}$ & $\begin{array}{c}\text { Density } \\
\text { (ind.sample }{ }^{-1} \text { ) }\end{array}$ & $\begin{array}{l}\text { Biomass } \\
\left(\text { g.sample }^{-1}\right)\end{array}$ & $\begin{array}{c}\mathrm{TL} \\
(\mathrm{mm})\end{array}$ & $\begin{array}{l}\mathrm{CL} \\
(\mathrm{mm})\end{array}$ & $\begin{array}{r}F W \\
(\mathrm{~g})\end{array}$ \\
\hline & & & & AKETZ & & & & & IZARO & & \\
\hline \multirow[t]{8}{*}{ West } & Intertidal & 573 & 882.9 & 33.1 & 12.0 & 1.5 & 60 & 178.3 & 41.6 & 19.1 & 3.0 \\
\hline & & 220 & 455.6 & 47.5 & 15.0 & 2.1 & 19 & 65.0 & 40.7 & 18.6 & 3.4 \\
\hline & & 229 & 606.6 & 43.9 & 15.4 & 2.7 & 26 & 85.9 & 38.6 & 19.1 & 3.3 \\
\hline & & 159 & 224.2 & 31.5 & 13.8 & 1.4 & 15 & 73.0 & 44.0 & 23.9 & 4.9 \\
\hline & Subtidal & 115 & 252.0 & 31.1 & 14.2 & 2.2 & 9 & 76.7 & 56.1 & 29.5 & 8.5 \\
\hline & & 57 & 172.6 & 34.2 & 17.7 & 3.0 & 139 & 108.0 & 20.3 & 9.7 & 0.8 \\
\hline & & 192 & 396.7 & 31.6 & 13.7 & 2.1 & 76 & 108.6 & 31.0 & 15.4 & 1.5 \\
\hline & & 135 & 480.1 & 41.7 & 18.1 & 3.6 & 33 & 64.9 & 31.8 & 16.7 & 2.0 \\
\hline \multirow[t]{9}{*}{ East } & Intertidal & 65 & 182.0 & 38.5 & 18.5 & 2.8 & 22 & 38.7 & 31.3 & 15.5 & 1.8 \\
\hline & & 139 & 332.5 & 36.0 & 17.1 & 2.4 & 18 & 26.9 & 28.7 & 16.0 & 1.5 \\
\hline & & 87 & 209.6 & 34.4 & 14.8 & 2.4 & 30 & 69.0 & 39.0 & 18.9 & 2.3 \\
\hline & & 57 & 265.0 & 56.0 & 24.0 & 4.7 & 13 & 35.3 & 35.0 & 18.6 & 2.7 \\
\hline & Subtidal & 81 & 111.3 & 25.0 & 12.5 & 1.4 & 45 & 110.8 & 38.8 & 16.5 & 2.5 \\
\hline & & 115 & 285.7 & 33.4 & 13.3 & 2.5 & 10 & 28.8 & 30.5 & 21.1 & 2.9 \\
\hline & & 99 & 286.1 & 41.3 & 17.9 & 2.9 & 20 & 50.5 & 32.8 & 19.5 & 2.5 \\
\hline & & 69 & 409.6 & 65.2 & 25.6 & 5.9 & 27 & 79.9 & 35.4 & 20.8 & 3.0 \\
\hline & & \multicolumn{6}{|c|}{ GAZTELUGATXE } & \multicolumn{4}{|c|}{ OGOÑO } \\
\hline \multirow[t]{8}{*}{ West } & Intertidal & 151 & 270.1 & 31.5 & 15.9 & 1.8 & 67 & 230.7 & 53.4 & 16.6 & 3.4 \\
\hline & & 160 & 254.5 & 25.8 & 13.1 & 1.6 & 68 & 138.4 & 44.5 & 15.7 & 2.0 \\
\hline & & 293 & 292.2 & 19.0 & 10.1 & 1.0 & 155 & 181.9 & 27.7 & 11.0 & 1.2 \\
\hline & & 355 & 255.7 & 17.7 & 9.5 & 0.7 & 110 & 220.6 & 35.6 & 13.3 & 2.0 \\
\hline & Subtidal & 1038 & 562.3 & 16.1 & 7.6 & 0.5 & 62 & 104.2 & 29.1 & 11.9 & 1.7 \\
\hline & & 358 & 418.5 & 24.2 & 12.1 & 1.2 & 84 & 154.5 & 30.3 & 13.7 & 1.8 \\
\hline & & 302 & 408.0 & 26.0 & 13.8 & 1.4 & 124 & 239.9 & 33.5 & 13.3 & 1.9 \\
\hline & & 300 & 398.8 & 24.4 & 13.0 & 1.3 & 76 & 109.4 & 23.8 & 11.5 & 1.4 \\
\hline \multirow[t]{8}{*}{ East } & Intertidal & 177 & 184.5 & 24.2 & 12.5 & 1.2 & 31 & 69.1 & 33.4 & 19.0 & 2.2 \\
\hline & & 101 & 169.1 & 32.8 & 16.1 & 1.7 & 104 & 151.8 & 32.3 & 14.2 & 1.5 \\
\hline & & 68 & 191.3 & 46.9 & 19.9 & 2.8 & 54 & 125.4 & 37.1 & 18.2 & 2.3 \\
\hline & & 144 & 417.1 & 45.2 & 19.6 & 2.9 & 70 & 123.6 & 34.3 & 17.5 & 1.8 \\
\hline & Subtidal & 118 & 231.8 & 29.1 & 15.7 & 2.0 & 51 & 116.5 & 29.7 & 18.2 & 2.3 \\
\hline & & 137 & 212.3 & 28.5 & 14.3 & 1.5 & 74 & 92.2 & 20.8 & 14.2 & 1.3 \\
\hline & & 238 & 190.6 & 15.6 & 9.1 & 0.8 & 89 & 106.7 & 20.8 & 13.1 & 1.2 \\
\hline & & 128 & 252.1 & 26.9 & 15.0 & 2.0 & 77 & 124.9 & 25.6 & 16.1 & 1.6 \\
\hline
\end{tabular}

TABLE 2. - Comparison of density, biomass, capitulum length and total length: (a) between protected and non-protected areas, for each orientation and tidal level; (b) between tidal levels for protected and non-protected areas, for each orientation; and (c) between orientations, for protected and non-protected areas and each tidal level. Kruskal-Wallis (K-W) and Kolmogorov-Smirnov (K-S) statistical and p-values are presented, for each comparison. Significant differences $(\mathrm{p}<0.05)$ are underlined. $(-)$ A non-orthogonal test was not undertaken, because there are no differences between locations.

\begin{tabular}{|c|c|c|c|c|c|c|c|c|}
\hline \multirow[b]{2}{*}{ Protection } & \multicolumn{2}{|c|}{ Density } & \multicolumn{2}{|c|}{ Biomass } & \multicolumn{2}{|c|}{ Capitulum length } & \multicolumn{2}{|c|}{ Total length } \\
\hline & $\mathrm{K}-\mathrm{W}$ statistic & $p$ & K-W statistic & $p$ & K-W statistic & $p$ & K-W statistic & $p$ \\
\hline Non-exposed intertidal & 6.35 & $\underline{0.012}$ & 11.29 & $\underline{0.001}$ & 5.83 & $\underline{0.016}$ & - & - \\
\hline Non-exposed subtidal & 8.65 & $\overline{0.003}$ & 9.93 & $\overline{0.002}$ & 0.01 & $\overline{0.916}$ & 0.01 & 0.916 \\
\hline Exposed intertidal & 10.60 & $\underline{0.001}$ & 10.60 & $\underline{\underline{0.001}}$ & - & - & - & - \\
\hline Exposed subtidal & 5.84 & $\underline{0.016}$ & 10.60 & $\underline{0.001}$ & - & - & - & - \\
\hline Tidal Level & K-S statistic & $p$ & K-S statistic & $p$ & K-S statistic & $p$ & K-S statistic & $p$ \\
\hline Non-protected non-exposed & 0.50 & 0.964 & 0.75 & 0.627 & 0.75 & 0.627 & 0.25 & 1.000 \\
\hline Non-protected exposed & 0.75 & 0.627 & 0.75 & 0.627 & 1.00 & 0.271 & 1.25 & 0.088 \\
\hline Protected non-exposed & 0.75 & 0.627 & 0.75 & 0.627 & 1.25 & 0.088 & 1.50 & 0.022 \\
\hline Protected exposed & 0.75 & 0.627 & 0.75 & 0.627 & 0.50 & 0.964 & 1.25 & 0.088 \\
\hline Orientation & K-S statistic & $p$ & $\mathrm{~K}-\mathrm{S}$ statistic & $p$ & K-S statistic & $p$ & K-S statistic & $p$ \\
\hline Non-protected intertidal & 0.75 & 0.627 & 1.00 & 0.271 & 0.50 & 0.964 & 1.25 & 0.088 \\
\hline Non-protected subtidal & 0.75 & 0.627 & 0.50 & 0.964 & 0.75 & 0.627 & 0.50 & 0.964 \\
\hline Protected intertidal & 1.75 & $\underline{0.004}$ & 1.25 & 0.088 & 1.25 & 0.088 & 1.00 & 0.271 \\
\hline Protected subtidal & 1.00 & $\overline{0.271}$ & 1.25 & 0.088 & 0.50 & 0.964 & 0.50 & 0.964 \\
\hline
\end{tabular}


TABLE 3. - Allometric relationships for each of the locations. Key: FW=fresh weight; DW=dry weight; TL=total length; $C L=$ capitulum length; $\mathrm{r}=$ correlation; $\mathrm{r}^{2}=$ explained variability $(\%) ; p$-significance; and $* * *$ significant correlation, at $p<0.001$.

\begin{tabular}{|c|c|c|c|c|c|}
\hline Location & Regression Equation & Data number & $\mathrm{r}$ & $\mathrm{r}^{2}$ & $p$ \\
\hline \multicolumn{6}{|c|}{ Fresh Weight and Total Length } \\
\hline Aketze & $\mathrm{FW}=1.210^{-5} \mathrm{x} \mathrm{TL}^{3.11}$ & 2,391 & 0.952 & 90.7 & $0 * * *$ \\
\hline Izaro & $\mathrm{FW}=6.610^{-5} \times \mathrm{TL}^{2.83}$ & 559 & 0.950 & 90.9 & 0 *** \\
\hline Ogoño & $\mathrm{FW}=6.910^{-5} \times \mathrm{TL}^{2.76}$ & 1,295 & 0.958 & 91.7 & $0 * * *$ \\
\hline Gaztelugatxe & $\mathrm{FW}=2.210^{-5} \mathrm{x} \mathrm{TL}^{3.09}$ & 4,048 & 0.969 & 94.1 & 0 *** \\
\hline \multicolumn{6}{|c|}{ Dry Weight and Total Length } \\
\hline Aketze & $\mathrm{DW}=4.910^{-5} \times \mathrm{TL}^{2.52}$ & 327 & 0.906 & 81.9 & $0 * * *$ \\
\hline Izaro & $\mathrm{DW}=3.810^{-5} \times \mathrm{TL}^{2.76}$ & 106 & 0.923 & 85.3 & $0 * * *$ \\
\hline Ogoño & $\mathrm{DW}=7.1 \quad 10^{-5} \times \mathrm{TL}^{2.56}$ & 234 & 0.929 & 86.3 & $0 * * *$ \\
\hline Gaztelugatxe & $\mathrm{DW}=1.410^{-4} \times \mathrm{TL}^{2.41}$ & 383 & 0.917 & 84.1 & 0 *** \\
\hline \multicolumn{6}{|c|}{ Fresh Weight and Capitulum Length } \\
\hline Aketze & $\mathrm{FW}=6.210^{-5} \mathrm{x} \mathrm{CL}^{3.5}$ & 2,391 & 0.955 & 91.3 & $0 * * *$ \\
\hline Izaro & $\mathrm{FW}=5.110^{-4} \mathrm{x} \mathrm{CL}^{2.81}$ & 559 & 0.981 & 96.3 & 0 *** \\
\hline Ogoño & $\mathrm{FW}=4.910^{-4} \mathrm{x} \mathrm{CL}^{2.84}$ & 1,295 & 0.983 & 96.5 & $0 * * *$ \\
\hline Gaztelugatxe & $\mathrm{FW}=1.110^{-4} \times \mathrm{CL}^{3.29}$ & 4,048 & 0.979 & 96.0 & $0 * * *$ \\
\hline \multicolumn{6}{|c|}{ Dry Weight and Capitulum Length } \\
\hline Aketze & $\mathrm{DW}=9.810^{-5} \times \mathrm{CL}^{3.09}$ & 327 & 0.990 & 98.2 & $0 * * *$ \\
\hline Izaro & $\mathrm{DW}=3.610^{-4} \times \mathrm{CL}^{2.67}$ & 106 & 0.968 & 93.8 & $0 * * *$ \\
\hline Ogoño & $\mathrm{DW}=5.310^{-4} \times \mathrm{CL}^{2.58}$ & 234 & 0.973 & 94.7 & $0 * * *$ \\
\hline Gaztelugatxe & $\mathrm{DW}=1.410^{-4} \times \mathrm{CL}^{2.99}$ & 383 & 0.980 & 96.1 & $0 * * *$ \\
\hline \multicolumn{6}{|c|}{ Dry Weight and Fresh Weight } \\
\hline Áketze & $\mathrm{DW}=0.08+0.40 \mathrm{FW}$ & 327 & 0.982 & 96.5 & $0 * * *$ \\
\hline Izaro & $\mathrm{DW}=0.08+0.40 \mathrm{FW}$ & 106 & 0.984 & 96.9 & $0 * * *$ \\
\hline Ogoño & $\mathrm{DW}=0.07+0.44 \mathrm{FW}$ & 234 & 0.983 & 96.6 & $0 * * *$ \\
\hline Gaztelugatxe & $\mathrm{DW}=0.08+0.47 \mathrm{FW}$ & 383 & 0.983 & 96.7 & $0 * * *$ \\
\hline
\end{tabular}

There are no significant differences in total length between locations for any orientation or tidal level $(p>0.05)$, except for non-exposed (NE-orientated) subtidal locations (Table 2). However, even at these locations, mean total length is not significantly higher in protected areas than in non-protected areas.

When comparing the tidal levels, the only significant differences $(\mathrm{p}<0.05)$ are found in the protected and non-exposed (NE-orientated) locations, where the total length of the barnacles is higher at the intertidal level (Table 2).

When comparing the two orientations (NE and $\mathrm{NW}$ ), significant differences $(p<0.05)$ are found only in the protected intertidal sampling stations, where the density is higher in exposed stations than in non-exposed stations (Table 2).

All the biometric relationships are highly significant (Table 3), with the coefficient relating length (total or capitulum) and weight (fresh or dry) around 3 , with a large number of individuals studied (between 559 and $4,048 \mathrm{~g}$, in the case of FW, and between 106 and $383 \mathrm{~g}$ in DW). The smallest coefficients are reached at Izaro and Ogoño (values from 2.58 to 2.84), and are highest at Aketze and Gaztelugatxe (2.99 to 3.5). The variability explained by the relationships lies between 90 and $98 \%$, with the exception being the total length/dry weight relationship (Table 3).

TABLE 4. - Allometric relationships between capitulum length (CL) and dry weight (DW), depending on the tidal level, orientation and protection in the locations. The comparison between regression lines was made after log-transforming data sets. Key: $r=$ correlation; $r^{2}=$ explained variability $(\%)$; and $p$-significance; $* * *$ significant correlation at $p<0.001$.

\begin{tabular}{|c|c|c|c|c|c|}
\hline Tidal Level & Regression Equation & Data number & $\mathrm{r}$ & $\mathrm{r}^{2}$ & $p$ \\
\hline Intertidal & $\mathrm{DW}=2.410^{-4} \times \mathrm{CL}^{2.81}$ & 516 & 0.972 & 94.6 & $0 * * *$ \\
\hline Subtidal & $\mathrm{DW}=3.210^{-4} \times \mathrm{CL}^{2.73}$ & 536 & 0.977 & 95.4 & $0 * * *$ \\
\hline Comparison & on lines & 1,042 & 0.971 & 95.1 & $0 * * *$ \\
\hline \multicolumn{6}{|l|}{ Orientation } \\
\hline NW & $\mathrm{DW}=3.410^{-4} \times \mathrm{CL}^{2.71}$ & 688 & 0.973 & 94.6 & $0 * * *$ \\
\hline $\mathrm{NE}$ & $\mathrm{DW}=1.110^{-4} \times \mathrm{CL}^{3.05}$ & 364 & 0.987 & 97.3 & $0 * * *$ \\
\hline Comparison & on lines & 1,042 & 0.976 & 95.3 & $0 * * *$ \\
\hline \multicolumn{6}{|l|}{ Protection } \\
\hline No & $\mathrm{DW}=5.010^{-4} \times \mathrm{CL}^{2.59}$ & 342 & 0.971 & 94.3 & $0 * * *$ \\
\hline Yes & $\mathrm{DW}=1.210^{-4} \times \mathrm{CL}^{3.04}$ & 711 & 0.986 & 97.2 & $0 * * *$ \\
\hline \multicolumn{2}{|c|}{ Comparison between regression lines } & 1,053 & 0.979 & 95.9 & $0 * * *$ \\
\hline
\end{tabular}


However, the allometric coefficients are higher in the intertidal, NE-orientated and unexploited locations (Table 4); this indicates that individuals here weigh more, for the same size, than in the subtidal, NW-orientated and exploited locations. The correlations are highly significant in these particular cases (Table 4). In all cases comparison between the regression lines shows highly significant differences (Table 4), even in the slopes and intercepts.

The juveniles ( $<10 \mathrm{~mm}$ capitulum length) were more abundant in the subtidal $(51.5 \%)$, rather than the intertidal $(41 \%)$ locations; they were more abundant in NW-orientated (52.1\%) than NE-orientated (34.4\%) locations. Similarly, juveniles were more abundant in unexploited $(50.6 \%)$ than exploited $(33 \%)$ locations. All of these differences were significant $(p<0.05)$.

\section{DISCUSSION}

Some of the reasons for establishing marine reserves include, amongst others: (i) protecting breeding stocks of certain commercially-important species; (ii) rehabilitating depleted stocks; (iii) protecting habitats representative of different coastal ecosystems; and (iv) conserving areas of outstanding richness and diversity (Attwood et al., 1997; Botsford et al., 2003). Hence, the role of marine protected areas in fisheries management is in relation to the importance of conserving ecosystem structure, as the framework for stable fishery production; likewise, in utilising the value of undisturbed ecosystems, for comparative studies, among others (Attwood et al., 1997).

In the Basque Country, there are significant differences concerning the density and biomass between the exploited and protected locations; they are both higher in the latter case (as mentioned also by Halpern (2003)). A similar pattern was revealed by the number of large individuals within the capitulum length of $>22.5 \mathrm{~mm}$. Hence, in protected locations (Aketze and Gaztelugatxe) individuals exceeding this length represent $24.3 \%$ of the total; at exploited locations (Izaro and Ogoño), this represents only $19.2 \%$ (with differences being significant at $p<0.05$ ). Cunha and Weber (2001) found it difficult to find individuals larger than $22.5 \mathrm{~mm}$ in capitulum length in overexploited areas. Once again, this demonstrates the success of the marine reserve in accomplishing the reasons outlined by Attwood et al. (1997) and Botsford et al. (2003), for their establishment.

Similarly to the above-mentioned authors, Hockey and Branch (1997) identified a set of 17 criteria for determining whether a marine reserve is achieving the objectives of its creation; two of these (does the area support exploited species?; and will the area supply stocks to adjacent areas?) are related directly to some of the objectives involved in creating the reserve at Gaztelugatxe.

With growing worldwide pressure to increase the level of protection afforded to marine habitats, partial fishing closures are often advocated by groups with direct fishing interests (Denny and Babcock, 2004). Such partial closures are promoted as a 'compromise' solution, allowing both protection and fishing (Willis and Denny, 2000). Other fishing management measures against overexploitation of goose barnacles are related to temporal closures, such as in Galicia (NW of Spain) (Molares and Freire, 2003) or Brittany (NW of France) (Girard, 1982), followed by a co-management system, shared between fisher organisations and fishery authorities.

The genus Pollicipes is very selective in terms of settlement, preferring areas exposed to waves and currents (Barnes and Reese, 1960; Barnes, 1996). This suggestion agrees with the results from the Basque coast because, in the NW-orientated locations where the waves break with high energy (González et al., 2004), there are higher density and biomass values (with significant differences) than in the NE-orientated locations (more protected). Moreover, there are also more juveniles $(52.1 \%)$ in the NW than in the NE (34.4\%) locations. The relationship between the distribution and abundance of the goose barnacle and the wave regime and energy has been tested and proved by Borja et al. (2004, 2006) for the area.

The allometric relationship between size $(\mathrm{mm})$ and weight $(\mathrm{g}$ ) in the Basque Country (the present contribution) fits with a multiplicative regression model. According to this relationship, the individuals are significantly heavier at the intertidal and protected locations, than at the subtidal and nonprotected locations. The protected areas, in our contribution, have higher regression coefficient values (with b near to 3 ) than the exploited areas (b near to 2.5); this suggests an unmodified relationship between length and weight within the Marine Reserve of Gaztelugatxe. The allometric relation- 
ship between size and weight, as obtained by Molares $(1993,1998)$ for $P$. pollicipes in Galicia, fits with a second-order polynomial equation; for comparison, Goldberg (1984) determined a linear relationship $(\log \mathrm{FW}=1.142 * \mathrm{CL}-1.645)$. Taking into account these relationships, the Galician goose barnacles have $25 \%$ more weight, for the same capitulum length, than those from the Basque coast. The same pattern is found when making comparisons with the Canadian Pollicipes polymerus (Bernard, 1988).

Cruz (1993), when studying three Portuguese locations, found that the weight and peduncle length are larger in individuals from locations with more immersion time; here, the food availability is higher. In contrast, along the Basque coast and according to the results obtained in the present contribution, the intertidal individuals are heavier and larger than at subtidal locations.

The lower number of juveniles found in the exploited locations in the present contribution, could be related to: (i) removal of adults, reducing the availability of suitable settlement sites for juveniles; or (ii) juveniles attached to adults being removed by fishermen, as described by Lauzier (1999a and b). Even if the proportion of adults $(>10 \mathrm{~mm})$ is higher at the exploited locations $(67 \%$ compared to $49.4 \%$ in protected locations), the density is much lower (see Table 1). Furthermore, size is considered a fundamental factor affecting fecundity of the genus Pollicipes, with small animals $(<15 \mathrm{~mm})$ producing around 16,200 eggs per brood and large animals $(>19 \mathrm{~mm})$ more than 34,000 (Cruz and Araújo, 1999; Cunha and Weber, 2001). Hence, taking into account the smaller mean size and the smaller mean weight, at the Izaro and Ogoño exploited areas, this could produce lower fecundity in these locations. Consequently, the role of these two effects underlines the impact of fishermen's activities, over the fecundation capabilities of exploited populations.

As a conclusion, the Gaztelugatxe Marine Reserve has significant differences in comparison with non-protected areas in preserving the goose barnacle population in terms of higher density, biomass, allometric coefficients, percentage of juveniles, and mean individual size. Hence, this reserve plays the same role as other fishing management measures against overexploitation, such as partial or temporal closures (Girard, 1982; Molares and Freire, 2003; and Bald et al., 2006).

\section{ACKNOWLEDGEMENTS}

This study was supported by a contract undertaken between the Department of Agriculture and Fishing of the Basque Government and AZTITecnalia. One of the authors (I. Muxika) was supported by a grant from the Technological Centres Foundation of the Basque Country. We also wish to thank Professor Michael Collins (School of Ocean and Earth Science, University of Southampton, UK) for kindly advising us on some details of this paper. Likewise, the sampling team and technicians of AZTI and Eneko Bachiller and Unai Otxotorena, for helping with the sampling and laboratory works. Finally, the comments of one anonymous reviewer and those from Enrique Ballesteros (CEAB-CSIC) have greatly improved the initial manuscript.

\section{REFERENCES}

Attwood, C.G., B.Q. Mann, J. Beaumont and J.M. Harris. - 1997. Review of the state of marine protected areas in South Africa. S. Afr. J. Mar. Sci., 18: 341-367.

Bald, J., A. Borja and I. Muxika. - 2006. A system dynamics model for the management of the gooseneck barnacle (Pollicipes pollicipes) in the Marine Reserve of Gaztelugatxe (Northern Spain), Ecol. Model., 194: 306-315.

Barnes, M. - 1996. Pedunculate cirripedes of the genus Pollicipes. Oceanog. Mar. Biol.: Ann. Rev., 34: 303-394.

Barnes, M. and E.S. Reese. - 1960. The behaviour of the stalked intertidal barnacle Pollicipes polymerus, J.B. Sowerby, with special reference to its ecology and distribution. J. Anim. Ecol., 29: 169-185.

Barybina, I.A. and L.V. Sanina. - 1975. Regression analysis of the relationships between the size and weight of molluscs. Hydrobiol. J., 11: 23-29.

Bernard, F.R. - 1988. Potential fishery for the gooneseck barnacle Pollicipes polymerus (Sowerby, 1833) in British Columbia. Fish. Res., 6: 287-298.

Borja, Á., R. Castro, J. Bald, V. Valencia, M. González and J. Franco. - 1999. La investigación para la declaración de biotopos marinos protegidos en el País Vasco: los casos de Gaztelugatxe, Izaro-Ogoño y Algorri. Actas de las I Jornadas Internacionales sobre Reservas Marinas, Murcia, 359-372.

Borja, A., V. Valencia, R. Castro, J. Franco, J. Bald, A. Uriarte, M. Mendizábal and F. Aguirrezabalaga. - 2000. Establecimiento de las bases técnicas de conocimiento del área de San Juan de Gaztelugatxe con vistas a su posible declaración como reserva marina. Informes Técnicos (Departamento de Agricultura y Pesca, Gobierno Vasco), 87: 152 pp.

Borja, A., J. Bald, I. Muxika and P. Liria. - 2004. El recurso marisquero de percebe (Pollicipes pollicipes) en el biotopo marino protegido de Gaztelugatxe y en áreas explotadas de Bizkaia, Informes Técnicos (Departamento de Agricultura y Pesca, Gobierno Vasco), 101: 1-108.

Borja, A., P. Liria, I. Muxika and J. Bald. - 2006. Relationships between wave exposure and biomass of the goose barnacle (Pollicipes pollicipes, Gmelin, 1790) in the Gaztelugatxe Marine Reserve (Basque Country, northern Spain). ICES J. Mar. Sci., 63(4): 626-636.

Botsford, L.W., F. Micheli and A. Hastings. - 2003. Principles for the design of marine reserves. Ecol. Appl., 13 (1) Suppl.: S25-S31.

Castro, R., A. Uriarte, A. Martínez de Murguía and Á. Borja. 2004. Biodiversity and conservation of wildlife and natural habitats. In: A. Borja and M. Collins (eds.), Oceanography and 
Marine Environment of the Basque Country, Elsevier Oceanography Series, 70: 531-548. Elsevier, Amsterdam.

Cruz, T. - 1993. Growth of Pollicipes pollicipes (Gmelin, 1790) (Cirripedia, Lepadomorpha) on the SW coast of Portugal. Crustaceana, 65:151-158.

Cruz, T. and J. Araujo. - 1999. Reproductive patterns of Pollicipes pollicipes (Cirripedia: Lepadomorpha) on the southwestern coast of Portugal. J. Crust. Biol., 19(2): 260-267.

Cruz, T and S.J. Hawkins. - 1998. Reproductive cycle of Pollicipes pollicipes at Cabo de Sines, south-west coast of Portugal. J. Mar. Biol. Assoc. U.K., 78(2): 483-496.

Cunha, I. and M. Weber. - 2001. Actividad reproductora del percebe Pollicipes pollicipes en el norte de Portugal. Libro de resúmenes VII Congreso Nacional de Acuicultura. Ed. Dirección General de Pesca y Alimentación (Gobierno de Cantabria). 173-175 pp.

Denny, C.M. and R.C. Babcock. - 2004. Do partial marine reserves protect reef fish assemblages? Biol. Conserv., 116: 119-129.

De la Hoz, J.J. and L. García. - 1993. Datos para el estudio de la distribución y reproducción del percebe, Pollicipes cornucopiae (Leach), en Asturias. Publ. Esp. Inst. Esp. Oceanogr., 11: 65-71.

Franco, J., J. Etxezarreta, A. Galarza, G. Gorospe and J. Hidalgo. 2004. Seabird populations. In: A. Borja and M. Collins (eds.), Oceanography and Marine Environment of the Basque Country, Elsevier Oceanography Series, 70: 515-530. Elsevier, Amsterdam.

Girard, S. - 1982. Etude du stock de pouces-pieds de Belle-île et de son exploitation. Mémoire de fin d'études.

Goldberg, H. - 1984. Posibilidades de cultivo de percebe, Pollicipes cornucopia Leach, en sistemas flotantes. Inf. Téc. Inst. Esp. Oceanogr., 11: 1-13.

González, M., A. Uriarte, A. Fontán, J. Mader and P. Gyssels. 2004. Marine Dynamics. In: A. Borja and M. Collins (eds.), Oceanography and Marine Environment of the Basque Country, Elsevier Oceanography Series, 70: 133-158. Elsevier, Amsterdam.

Halpern, B.S. - 2003. The impact of marine reserves: do reserves work and does reserve size matter? Ecol. Appl., 13(1) Suppl.: S117-S137.

Hockey, P.A.R. and G.M. Branch. - 1997. Criteria, objectives and methodology for evaluating marine protected areas in South Africa. South Afr. J. Mar. Sci., 18: 369-383.

IUCN. - 1992. Caracas action plan. In: Plenary Session and Symposium Papers of the Ivth World Congress on National
Parks and Protected Areas, Caracas, Venezuela, Gland, Switzerland; World Conservation Union (IUCN): 301-310.

Jamieson, G.S. and C.O. Levings. - 2001. Marine protected areas in Canada -implications for both conservation and fisheries management. Can. J. Fish. Aquat. Sci., 58: 138-156.

Jamieson, G.S., R.B. Lauzier and G. Gillespie. - 1999. Phase 1. Framework for undertaking an ecological assessment for outer coast rocky intertidal zone. Fisheries and Oceans Canada, Canadian Stock Assessment Secretariat, Research Document 99/209: 1-33.

Lauzier, R.B. - 1999a. A review of the biology and fisheries of the goose barnacle (Pollicipes polymerus Sowerby, 1833). Fisheries and Oceans Canada, Canadian Stock Assessment Secretariat, Research Document 99/111: 1-30.

Lauzier, R.B. - 1999b. Framework for goose barnacle (Pollicipes polymerus Sowerby, 1833) fishery in waters off the west coast of Canada. Fisheries and Oceans Canada, Canadian Stock Assessment Secretariat, Research Document 99/198: 1-24.

Molares, J. - 1993. Estudio del ciclo biológico del percebe (Pollicipes cornucopia Leach) de las costas de Galicia. Alimentaria, 248: 9-70.

Molares, J. - 1998. Biología y explotación del percebe (Pollicipes cornucopia) en las costas de Galicia. En: Penas Patiño, X. (ed.) Marisqueo en Galicia: $3^{\mathrm{a}}$ Xornadas de Medio Mariño e Acuicultura. Edicios do Castro, Sada, 135-158.

Molares, J. and J. Freire. - 2003. Development and perspectives for community-based management of the goose barnacle (Pollicipes pollicipes) fisheries in Galicia (NW Spain). Fish. Res., 65: 485-492.

Nomura, E. - 1926. Further studies on the applicability of $a=k b x$ in expressing the growth relations in molluscan shells. Sci. Rep. Tohoku Imp. Univ., 2: 63-84.

Underwood, A.J. - 1992. Beyond BACI: the detection of environmental impacts on populations in the real, but variable, world. J. Env. Mar. Biol. Ecol., 161: 145-178.

Underwood, A.J. - 1997. Experiments in Ecology: their logical design and interpretation using analysis of variance. Cambridge University Press, Cambridge.

Willis, T.J. and C.M. Denny. - 2000. Effects of the Poor Knights Island Marine Reserve on demersal fish populations. Report to the Department of Conservation, Science and Research (Grant $\left.\mathrm{N}^{\circ} 2519\right)$

Scient. ed.: E. Ballesteros

Received April 5, 2005. Accepted January 17, 2006. 